\title{
Le Bel Ange
}

\section{Suniti Namjoshi}

(i)

One day an amorous angel said to me, "Tu es une belle Indienne." "Oh no," I said, "I don't speak French," and shuffled, but felt so very, so extraordinarily happy, I smiled. "Parmi toutes les femmes ici, je t'ai choisie," she said. "Oh golly," I said, tried not to gulp, but she didn't seem to mind. "J'aime tes bras, tes seins, tes cheveux, ton visage, ta voix, tes lèvres, ton corps, tes genoux," she said. I felt so embarrassed I dropped my eyes. But then this angel took me in her arms. "Que tu es belle!"' I said and was reconciled.

(Q. To what was I reconciled?

A. To having my knees admired.)

(ii)

Le deuxième jour l'ange m'a dit, "Il faut que tu changes." "What do you mean?" I said. "Do you mean my clothes?" "Pas tes vêtements," she said. I found myself melting in the light of her glance, et j'ai changé et je change encore. Bientôt elle trouvera qu'elle est la belle femme et que je suis l'ange.

(iii)

"Les anges, qu'est-ce-qu'ils font?" lui ai-je demandé.

“Est-ce-qu'ils peinent, est-ce-qu'ils filent, est-ce-qu'ils mangent?" "Pas du tout," a-t-elle répondu. "Ils aiment les belles femmes et ils chantent, ils chantent." Alors, j'ai su que ceci était mon métier et que je ferais mes devoirs comme un ange, un bel ange. 